\title{
Impact of nanosilver-profenofos on cotton leafworm, Spodoptera littoralis (Boisd.) larvae
}

\author{
Khaled Sayed Ahmed ${ }^{1 *}$ (D), Wafai Z. A. Mikhail ${ }^{2}$, Hassan M. Sobhy², Eman Mohamed Mostafa Radwan ${ }^{1}$ and
}

Taher A. Salaheldin ${ }^{3,4}$

\begin{abstract}
Background: The cotton leafworm, Spodoptera littoralis (Boisd.), is one of the most dangerous pests in Egypt and Africa, causing significant economic loss of cotton crop yield. The frequent use of insecticides to control this insect has led to the development of a generation's resistance to them. The need of a new, safe control method and effective insecticides has become necessary after the recent increases in environmental pollution and insect resistance. This study is devoted to developing a novel synthetic scheme to produce a pesticide nanocomposite of very high efficiency compared to the originals. The nature of its chemical binding has been investigated via Fourier transform-infrared (FT-IR) and transmission electron microscopy (TEM) techniques.

Results: In this work, the method is based on using silver nanoparticles (AgNPS) as a pesticide carrier by loading the organophosphorus pesticide profenofos on to their surface. The profenofos, AgNPS alone and nanocomposite profenofos (AgNPS@P) have been tested against second- and fourth-instar larvae of laboratory and field cotton leafworm. Our findings indicate that the AgNPS@P is more effective on cotton leafworm larvae than each of profenofos and nanosilver alone. The activity of AgNPS@P ( $\mathrm{LC}_{50}=0.94$ and $\left.5.15 \mathrm{ppm}\right)$ was increased to 85 and 69 times more than that of profenofos $\left(\mathrm{LC}_{50}=79.52\right.$ and $\left.356.97 \mathrm{ppm}\right)$ against second- and fourth-instar larvae of field cotton leafworm.
\end{abstract}

Conclusions: This method may be successful for reducing environmental pollution and the resistance of this pest to many pesticides.

Keywords: Cotton leafworm, Spodoptera littoralis, Organophosphorus pesticide, Profenofos, Nanosilver, Nanocomposite

\section{Background}

The loss of agricultural production by pests is estimate to be about $14-25 \%$ of the total production. Weeds have a direct effect on the size, quantity and quality of food security, which decreases agricultural crop production. Some insect pests are vectors of many diseases which cause serious problems to human health and others damage crops (Salahuddin et al. 2004).

The noctuid moth of the cotton leafworm, Spodoptera littoralis (Boisad.) (Lepidoptera: Noctuidae) is found

\footnotetext{
* Correspondence: khal20024sh8@gmail.com;

khal20024sh8@esjpesticides.org.eg

'Central Agricultural Pesticides Laboratory, Agricultural Research Centre, Giza, Egypt

Full list of author information is available at the end of the article
}

widely in Mediterranean Europe and Africa. This insect has been record in the UK at least six times, where it is also renowned either as the Mediterranean brocade, an immigrant or as a casual import. It often feeds on fruit, vegetables, flowers and field crops. Generally, the larvae prefer young leaves and, while they are consuming these, they are also feeding on other parts of the plant. Infestation frequently leads to complete defoliation and devouring of the leaves. The larvae interfere with plant development by destroying growth points and flowers as well as hollowing out the seed bolls, which often causes them to wilt and drop (Croft 1990). The Egyptian cotton leafworm, S. littoralis, is the most destructive pest of several crops such as cotton (Gossypium hirsutum (L.)), 


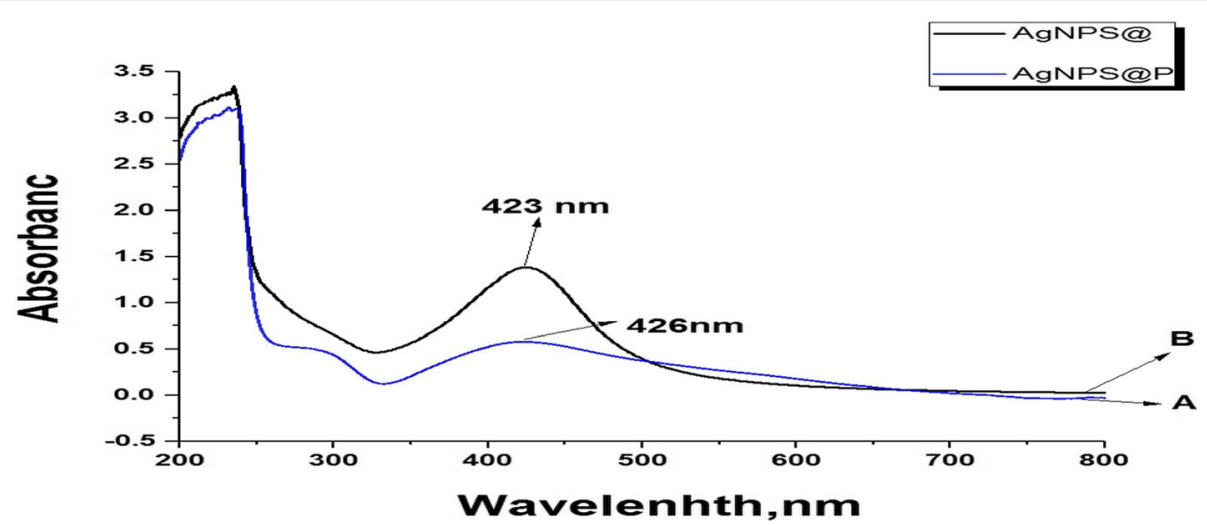

Fig. 1 The ultraviolet-visible (UV-VIS) spectrum of (A) AgNPS@P and (B) AgNPS only

peanut (Arachis hypogaea (L.)), soybean (Glycine max (L.)) and various vegetables in Europe, Africa and Asia (El-Aswad et al. 2003).

Insect resistance is a major problem generated by the frequent use of the conventional pesticides for controlling the insect pests (Nkya et al. 2014). The development of cotton leafworm resistance to the use of synthetic pyrethroids, organophosphorus, carbamates and other chemical insecticides has been correlated with the appearance of cross-resistance in many cases (El-Zemaity et al. 2003). On the other hand, the use of pesticides causes an increase in costs and many problems of environmental and personal exposure which has led to the contamination of ground waters, plants, soil, animals and damaging beneficial non-target organisms (Kuzma et al. 2006). In addition, many insecticides are not soluble in water, so large quantities of organic solvents are required and most of these solvents contaminate the environment (Sanni and Mutta 2014).

Profenofos

4-bromo-2-chloro-1-[ethoxy(propylsulfanyl)

phosphoryl]oxybenzene is also called phosphorothioic acid, O-(4-bromo-2-chlorophenyl) O-ethyl-S-propyl ester (free encyclopedia CAS Number 41198-08-7 from the pesticide manual). The profenofos mechanism of action is via inhibition of the acetylcholinesterase enzyme. Profenofos can be used on a variety of crops such as maize, potato, soybean, sugar beet, cotton and other vegetables. In the United States, it is used exclusively on cotton and is primarily used against lepidopteran insects. Profenofos can be used against the cotton mealybug, cabbage caterpillar, diamondback moth and asparagus caterpillars, as well as against wheat and cabbage aphids (FAO and WHO 2009). However, profenofos is toxic to birds, small mammals, bees, fish and aquatic invertebrates. Several fish-killing incidents have occurred in which profenofos exposure, primarily due to runoff, has been implicated as a probable cause (Onwuka 2015). Based on a study of patients poisoned with profenofos and its close chemical relative, prothiofos, the compounds have been described as moderately severe toxins that cause respiratory failure. Differences in chemical structure that distinguish these two compounds from more common organophosphorus pesticides - namely, the presence of the $S$-alkyl group on the phosphorus atom where most organophosphorus compounds
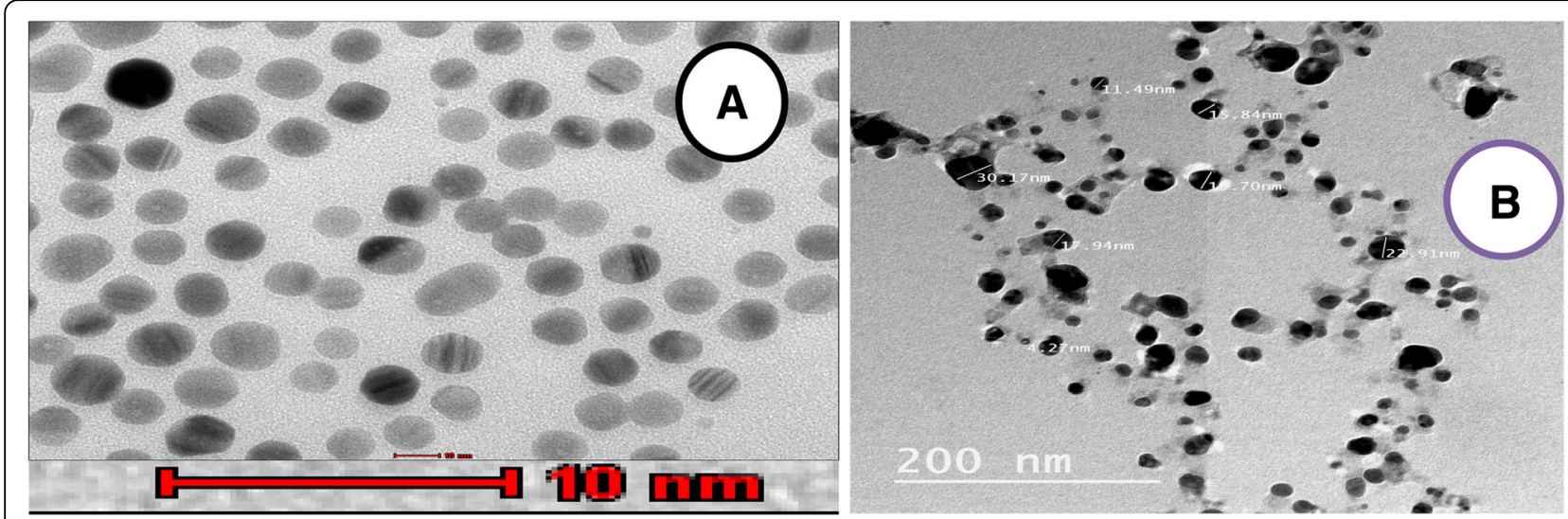

Fig. 2 The transmission electron micrographic image of a AgNPS only and $\mathbf{b}$ AgNPs@P 


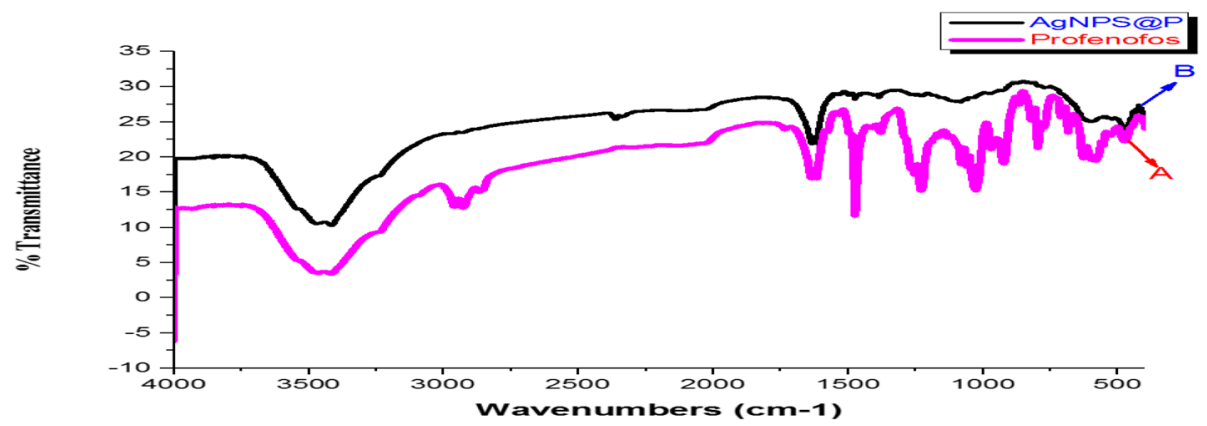

Fig. 3 The Fourier transform-infrared (FT-IR) spectra for (A) profenofos and (B) AgNPS@P

possess a methoxy or ethoxy group - underlie differences in their behavior as acetylcholinesterase enzyme inhibitors compared to the rest of the organophosphorus class (Eddleston et al. 2009).

Nanotechnology has been used over the last 10 years to potentially revolutionize agricultural practices. Some suggested applications, such as the development of precision farming devices or genetically modified crops, nanofungicides, nanoherbicides, nano-encapsulation and nanopesticides, can be of use (Zhang et al. 2013). Metal nanoparticles are unique because they show the potential to change their surfaces in order to introduce specific functionalities for environmental applications (Haick 2007). Nanopesticides present an appealing solution for pesticide problems because their effective concentrations are much lower compared to those of formulated pesticides and they are soluble in water without organic solvents. Recently, several publications reported on the evolution of nanopesticide formulations (Bhattacharyya et al. 2010). The target of nanopesticide composition for necessary world applications is to obtain nanoparticles with the following characteristics: (1) a constant and lean size distribution, (2) a well-known shape, (3) a chemical structure known to have no impurities and (4) no congregation or clotting properties (Sooresh et al. 2011). The use of a capping agent works as a colloidal stabilizer that enhances water suspension ability. These very eligible characteristics apply to silver nanoparticles because silver is an electron-dense metal (Rotello 2003).

This work is a trial to synthesize silver nanoparticles stabilized by starch as the form of encapsulation for the synthetic organophosphorus pesticide profenofos (using an inexpensive and reproducible method) and to characterize them. Also, the toxic effects of profenofos, silver nanoparticles (AgNPS) and nanocomposite profenofos (AgNPS@P) on larvae of the laboratory and field cotton leafworm can be evaluated.

Table 1 Toxicity effect of silver nanoparticles (AgNPS) and profenofos compared with nanoprofenofos (AgNPS@P) against secondinstar larvae of laboratory and field cotton leafworm, Spodoptera littoralis

\begin{tabular}{|c|c|c|c|c|c|c|c|c|c|c|c|c|c|c|}
\hline \multirow[t]{2}{*}{$\overline{\text { Strain }}$} & \multicolumn{4}{|c|}{ Silver (AgNPS) } & \multicolumn{5}{|c|}{ Profenofos } & \multicolumn{5}{|c|}{ Nanoprofenofos (AgNPS@P) } \\
\hline & $\begin{array}{l}\text { Conc. } \\
\text { ppm }\end{array}$ & $\begin{array}{l}\mathrm{M} \\
\text { (\%) }\end{array}$ & $\begin{array}{l}\mathrm{LC}_{50} \\
\text { in } \\
\text { ppm }\end{array}$ & $\overline{\mathrm{RR}^{\mathrm{a}}}$ & $\begin{array}{l}\text { Conc. } \\
\text { ppm }\end{array}$ & $\begin{array}{l}M \\
\text { (\%) }\end{array}$ & $\begin{array}{l}\mathrm{LC}_{50} \\
\text { in } \\
\text { ppm }\end{array}$ & $\mathrm{RR}^{\mathrm{a}}$ & $\mathrm{RRr}^{\mathrm{b}}$ & $\begin{array}{l}\text { Conc. } \\
\text { ppm }\end{array}$ & $\begin{array}{l}\text { M } \\
(\%)\end{array}$ & $\begin{array}{l}\mathrm{LC}_{50} \\
\text { in } \\
\text { ppm }\end{array}$ & $\mathrm{RR}^{\mathrm{a}}$ & $\mathrm{RRr}^{\mathrm{b}}$ \\
\hline \multirow[t]{7}{*}{ Laboratory } & & & 1000.9 & $-\overline{---}$ & 0.71 & 20 & 4.49 & ---- & 44.9 & 0.011 & 10 & 0.1 & ---- & 1 \\
\hline & & & & & 1.41 & 28 & & & & 0.023 & 24 & & & \\
\hline & 124.88 & 6 & & & 2.82 & 46 & & & & 0.045 & 30 & & & \\
\hline & 249.75 & 16 & & & 5.63 & 52 & & & & 0.09 & 44 & & & \\
\hline & 499.5 & 30 & & & 11.3 & 66 & & & & 0.18 & 60 & & & \\
\hline & 999 & 50 & & & 22.5 & 76 & & & & 0.36 & 74 & & & \\
\hline & & & & & 45 & 86 & & & & 1.44 & 90 & & & \\
\hline \multirow[t]{5}{*}{ Field } & & & 4109.6 & 4.11 & 22.5 & 14 & 79.52 & 17.7 & 84.6 & 0.18 & 10 & 0.94 & 9.4 & 1 \\
\hline & 187.31 & 6 & & & 45 & 36 & & & & 0.36 & 20 & & & \\
\hline & 374.63 & 10 & & & 90 & 56 & & & & 0.72 & 40 & & & \\
\hline & 749.25 & 20 & & & 180 & 70 & & & & 1.44 & 60 & & & \\
\hline & 1498.5 & 30 & & & 270 & 84 & & & & 2.88 & 86 & & & \\
\hline
\end{tabular}

${ }^{\mathrm{a}} \mathrm{RR}$ (Resistance Ratio) $=\mathrm{LC}_{50}$ of the field strain/LC $\mathrm{C}_{50}$ of the laboratory strain

${ }^{\mathrm{b}} \mathrm{RRr}$ (Relative Resistance ratio) $=\mathrm{LC}_{50}$ of the strain/lowest $\mathrm{LC} \mathrm{C}_{50}$ values of the same strain

$M$ mortality 

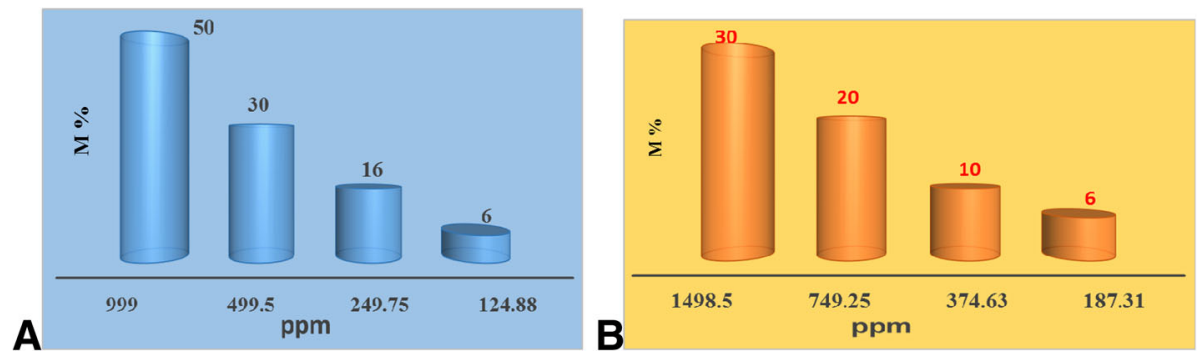

Fig. 4 The mortality percentages of second-instar larvae for AgNPS to a laboratory and $\mathbf{b}$ field strains of Spodoptera. littoralis

\section{Materials and methods \\ Chemicals}

These are silver nitrate $\left(\mathrm{AgNO}_{3}, 99.9 \%\right.$, with average molecular weight $=169.87$, produced by Alpha Chemika Co.), glucose $\left(\mathrm{C}_{6} \mathrm{H}_{12} \mathrm{O}_{6}, 99 \%\right.$ with average molecular weight $=180.2$, produced by El-Nasr Pharmaceutical Chemicals Co. $)$, soluble starch $\left(\left(\mathrm{C}_{6} \mathrm{H}_{10} \mathrm{O}_{5}\right)_{\mathrm{n}}, 99 \%\right.$ powdered solid with average molecular weight $=81.37$, produced by Chemajet Pharmaceutical Co.). Profenofos $\left(\mathrm{C}_{11} \mathrm{H}_{15} \mathrm{BrC}_{1 \mathrm{O}}\right.$.3PS, $98.9 \%$ with average molecular weight = 373.63) is produced by Dr. Ehrenstorfer GmbH, Empirical Formula (Hill Notation).

\section{Insects}

The laboratory insects are reared on castor bean plant leaves for 7 years, without any exposure to insecticides, in the Insect Population Toxicology Department, Central Agricultural Pesticides Laboratory (CAPL), Agriculture Research Centre, Ministry of Agriculture, Giza, Egypt under laboratory constant conditions $\left(25 \pm 2{ }^{\circ} \mathrm{C}\right.$ and 60 $\pm 5 \% \mathrm{R}$. $\mathrm{H}$ for a period of $16 \mathrm{~h}$. L: $8 \mathrm{~h}$. D) (Hatem et al. 2011). Field insects were collected as eggs from EL-Beheira Governorate, Egypt and reared, as mentioned before, for one generation.

\section{Synthesis and characterization of AgNPS and AgNPS@P Synthesis of silver nanoparticles and encapsulated nanoprofenofos}

Starch-silver nanoparticles encapsulate the profenofos, according to Nnemeka et al. (2016), with the modulation of encapsulation being completed in situ during synthesis of the silver nanoparticles by direct physical gelation (Nnemeka et al. 2016; Vimala et al. 2011 and Tali 2009). The synthesis was carried out via chemical reduction of silver nitrate by glucose as follows: a mixture of 0.06- $\mathrm{M} \mathrm{AgNO}_{3}$ and $0.2-\mathrm{M}$ glucose solution (1: 3 volume ratio) in a loosely covered flask containing $1 \%$ starch dispersion ( $1 \mathrm{~g}$ in $100 \mathrm{ml}$ distilled water), were added to $10 \mathrm{ml}$ of profenofos. The mixture was stirred and heated for $3 \mathrm{~h}$ and the resultant complex was cooled and centrifuged at $11,000 \mathrm{rpm}$ for $20 \mathrm{~min}$ using a Hettich-Mikro 22R centrifuge. Subsequently, each STAgNP-P nanocomposite (AgNPS@P) was precipitated the with addition of $30 \mathrm{ml}$ acetone, re-centrifuged at $6000 \mathrm{rpm}$ for $5 \mathrm{~min}$ and sediment oven-dried at $40^{\circ} \mathrm{C}$ for $24 \mathrm{~h}$. The nanocomposite was finely ground, kept in a sample bottle, and stored in a vacuum desiccator in the dark for further use and characterization.

\section{Characterization of AgNPS and AgNPS@P}

All prepared samples were characterized by transmission electron microscopy (TEM) as a base tool for scaling the particle size, structure and style, and the plasmonic effects were detect by ultraviolet-visible (UV-VIS) spectroscopy. The nature of the linkage between pesticide and AgNPS was investigated using Fourier transform-infrared (FT-IR) spectroscopy.

\section{UV-VIS spectral analysis}

The composition of the nanoparticles was detected using a UV-VIS spectrophotometer (Scan Software Version: 3 (182) Parameter List: Instrument Cary 5000, Instrument

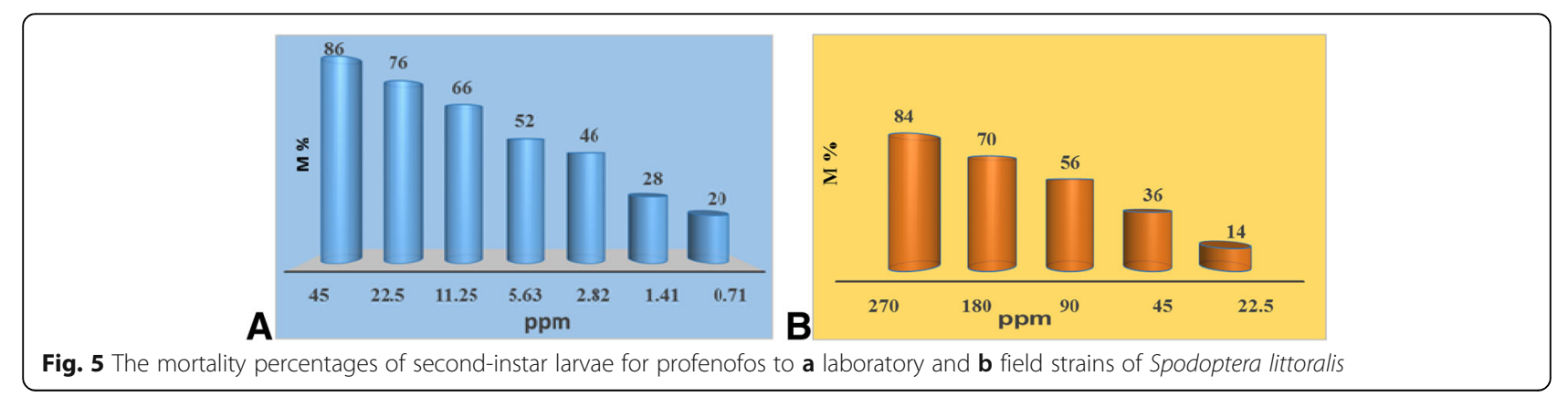



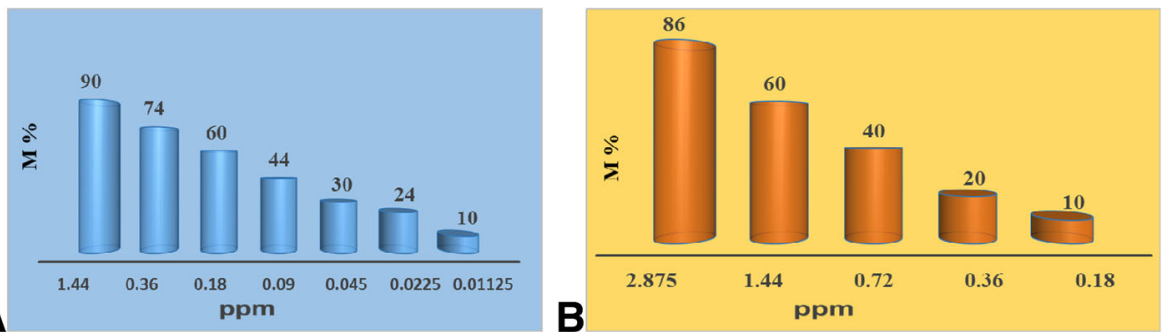

Fig. 6 The mortality percentages of second-instar larvae for AgNPS@P to a laboratory and $\mathbf{b}$ field strains of Spodoptera littoralis

Version 1.12, Start 800 (nm), Stop $200(\mathrm{~nm})$ ) in the Mammalian Toxicology Department of CAPL. Aliquots (3 $\mathrm{ml})$ of the suspension were measured to determine the surface plasmon resonance (SPR) absorption maxima with distilled water as a reference.

\section{Transmission electron microscopy (TEM imaging)}

The TEM images were carried out in the National Research Centre, Dokki, Giza, Egypt. Dispersed STAgNP-P samples in absolute ethanol were dropped on to coated copper grids and allowed ethanol to evaporate. Micrographs were obtained using a high-resolution transmission electron microscope (HR-TEM) (FEI TECNAI 02) with software TECNAI G2. The HR-TEM is a JOEL JEM-M2100 operating at $200 \mathrm{kV}$ equipped with a Gatan Erlangshen ES500 digital camera.

\section{Fourier transform-infrared (FT-IR) spectral analysis}

The FT-IR spectra were recorded by an AVATAR 330 FT-IR Thermo Nicolet (Software EZOMNIC V 6.1A) in the Pesticide Analysis Department of CAPL. The samples were scanned within a range of $400-4000 \mathrm{~cm}^{-1}$.

\section{Toxicity of AgNPS, profenofos and AgNPS@P against} second and fourth larval instars of the cotton leafworm The leaf-dip technique bioassay was applied to examine the effects of profenofos, AgNPS alone, and AgNPS@P against the second- and fourth-instar larvae of laboratory and field $S$. littoralis. Serial concentrations were prepared by dilution of the tested compounds with distilled water (Vimala et al. 2011). Clean castor bean leaves were dipped for $15 \mathrm{~s}$ in each compound concentration, and left to dry at room temperature then put in petri-dishes. Others were dipped in distilled water for the same period as the control. Five replicates were carried out for each concentration and control. Ten larvae of the second or fourth instars from each laboratory and field cotton leafworm were added to each treated and control dish. All the treated and untreated (control) larvae were allowed to feed on the leaves and all the samples were preserved at room temperature. Mortalities were recorded after $24 \mathrm{~h}$ (Thomas and Ralf, 2015).

\section{Statistical analysis}

The corrected mortality percentages were calculated by using Abbott's formula (Abbott 1925) and the sublethal concentration of pesticides statistically computed according to Tali (2009). The median lethal concentration $\left(\mathrm{LC}_{50}\right)$ was determined at the $95 \%$ confidence level $(P<$ 0.05) using the program Ldp Line, an application that calculates by probit analyses according to Finney (1971).

\section{Results}

Synthesis and characterization of AgNPS and AgNPS@P In this procedure, glucose and starch served the dual role of both a reducing agent and a stabilizer. Then, the core particles, AgNPS were combined with profenofos to produce AgNPS@P, which was also produced in ethanol as opposed to using harsh non-polar solvents. The characterizations of AgNPS and AgNPS@P are shown in detail.
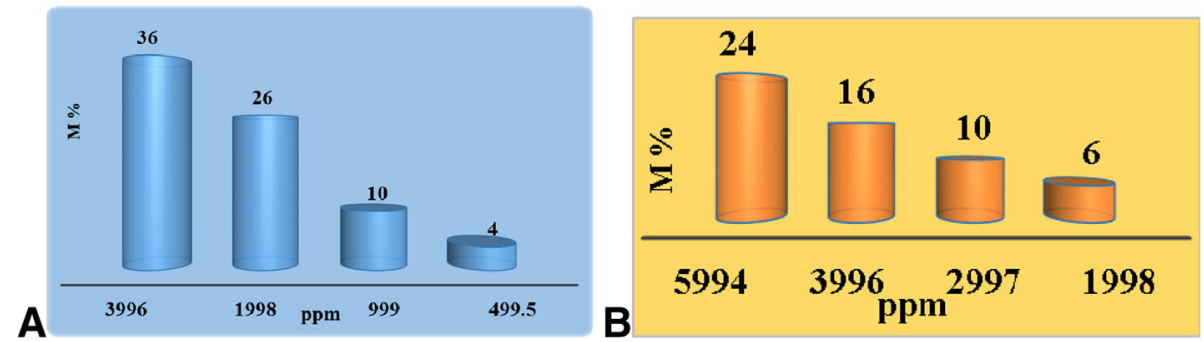

Fig. 7 The mortality percentage of fourth-instar larvae for AgNPS to a laboratory and $\mathbf{b}$ field strains of Spodoptera littoralis 

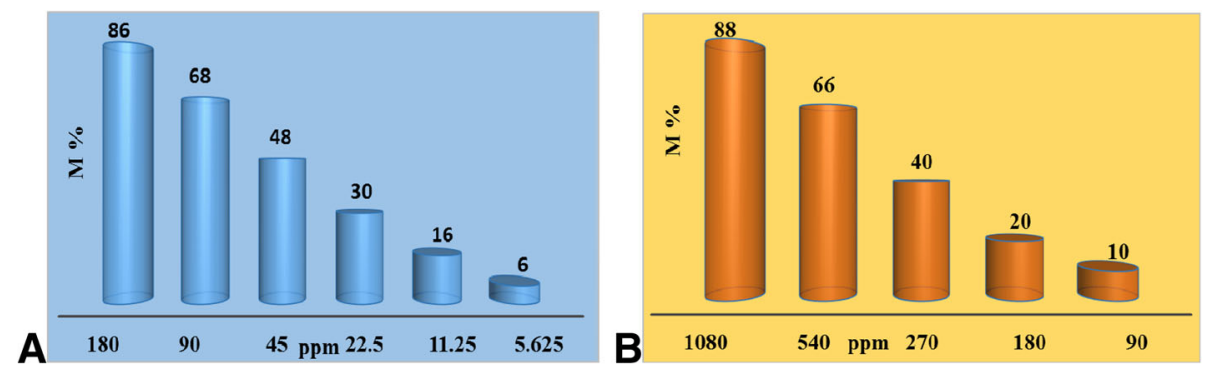

Fig. 8 The mortality percentages of fourth-instar larvae for profenofos to $\mathbf{a}$ laboratory and $\mathbf{b}$ field strains of Spodoptera littoralis

\section{UV-VIS absorption spectroscopy}

The first confirmation of the silver nanoparticles (AgNPS) and nanoprofenofos (AgNPS@P) is shown in Fig. 1. The obtained (AgNPS) and (AgNPS@P) both showed a broad spectral peak at 423 and $426 \mathrm{~nm}$, respectively.

\section{TEM imaging}

The size and shape of the silver colloid particles have been measure by TEM imaging. A representative TEM image of these particles is given in Fig. 2a. The particles are mostly spherical. From the sizes of numerous particles, measured on the TEM images, the average size (diameter) of the silver nanoparticles loaded with profenofos (AgNPS@P) is 11.49-30.17 nm.

\section{Fourier transform infrared (FT-IR) spectroscopy}

FT-IR spectroscopy of the starch-silver nanoparticles was registered agree the functional groups of glucose and starch interested in the reduction and capping/ stabilization as shown for profenofos (A) and AgNPS@P (B) (Fig. 3).

The broad, strong bands at 3416.40 and $3416.01 \mathrm{~cm}^{-1}$ are due to the $\mathrm{O}-\mathrm{H}$ stretching vibration for profenofos and AgNPS@P, respectively. Also, it is clear that, $\mathrm{C}-\mathrm{H}$ aliphatic vibrations appearing as peaks at 2960.26 and $2927.63 \mathrm{~cm}^{-1}$ correspond to the asymmetrical and symmetrical bending vibrations of the methylene groups for profenofos, while this peak disappeared at 2960.26 and $2927.63 \mathrm{~cm}^{-1}$ and appeared as a peak at 2360.98 for AgNPS@P. Aliphatic C-H appeared as two strong bands at $2962+10 \mathrm{~cm}^{-1}$ and $2872+10 \mathrm{~cm}^{-1}$ corresponding to asymmetrical and symmetrical stretching modes. The $\mathrm{C}=\mathrm{C}$ stretching vibrations for hetero-aromatic compounds were observed in the region $1600-1400 \mathrm{~cm}^{-1}$. Profenofos and AgNPS@P show this band at (1618.20 and $\left.1637.58 \mathrm{~cm}^{-1}\right)$ and $\left(1618.37\right.$ and $\left.1637.58 \mathrm{~cm}^{-1}\right)$, respectively.

\section{Toxic effects of nanosilver, profenofos and nanoprofenofos}

Nanosilver, profenofos and nanoprofenofos toxicity against second-instar larvae

The larvicidal activities of silver nanoparticles (AgNPS) alone, profenofos, and silver nanoparticle-loaded profenofos (AgNPS@P) were studied against second-instar larvae of each of laboratory and field S. littoralis. The results shown in Table 1 revealed that the mortality rate increased with an increase in the concentrations of the tested pesticides for the laboratory insects, where the mortality percentages ranged between 6 and 50\% with AgNPS concentrations of $124.88-999 \mathrm{ppm}$, and 6-30\% with AgNPS concentrations of 187.31-1498.5 ppm for field insects (Table 1 and Fig 4). These percentages ranged between 10 and 90\% with AgNPS@P concentrations of 0.01-1.44 ppm, compared with those of profenofos of 20-86\% with AgNPS@P concentrations of $0.71-45 \mathrm{ppm}$ for the laboratory strain (Table 1 and Fig. 5). Concerning the field strain, the percentages of mortality recorded were $10-86 \%$ with concentrations of 0.18-2.88 ppm for AgNPS@P and 14-84\% for concentrations of 22.5-270 ppm for profenofos (Table 1 and Fig. 6). The results of the concentration-dependent assay suggest that the comparison between the $\mathrm{LC}_{50}$ of

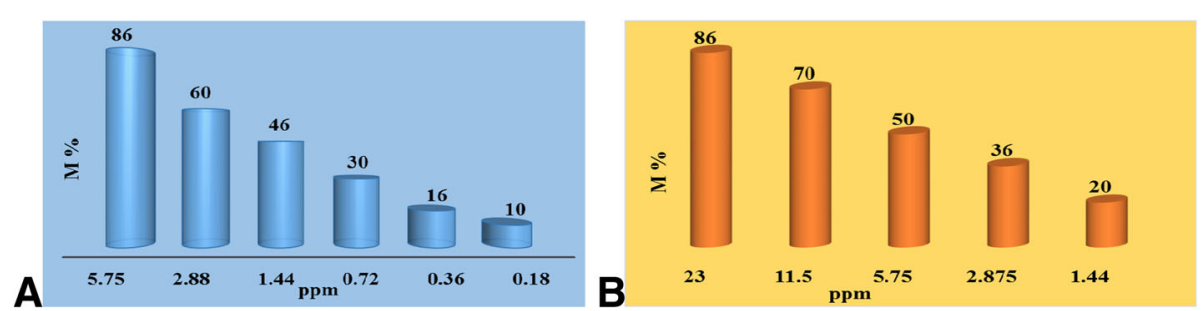

Fig. 9 The mortality percentages of fourth-instar larvae for AgNPS@P to a laboratory and $\mathbf{b}$ field strains of S. littoralis 
profenofos (4.49 ppm) and AgNPS@P (0.1 ppm) for second instar larvae of the laboratory strain produced a Relative Resistance ratio $(\mathrm{RRr})=44.9$ fold, i.e.

\section{Nanosilver, profenofos and nanoprofenofos toxicity against fourth-instar larvae}

The larvicidal activities of the silver nanoparticles (AgNPS), profenofos, and silver nanoparticle-loaded profenofos (AgNPS@P) against laboratory and field fourth-instar larvae of the cotton leafworm are shown in Table 2 and Figs. 7, 8 and 9. The mortality percentages of laboratory larvae ranged between 4 and 36\% with AgNPS concentrations of 499.5 to $3996 \mathrm{ppm}$ and the field strain ranged between 6 and $24 \%$ with concentrations of 1998 to $5994 \mathrm{ppm}$ (Table 2 and Fig. 7). The mortality ranged between 10 and $86 \%$ for laboratory larvae with AgNPS@P concentrations of 0.18 to $5.75 \mathrm{ppm}$ (Table 2 and Fig. 8) compared with those of profenofos 6 to $86 \%$ with concentrations of 5.625 to $180 \mathrm{ppm}$. In the case of field larvae, the percentages recorded were 20 to $86 \%$ with AgNPS@P concentrations of 1.44 to 23 ppm, compared to profenofos 10 and $88 \%$ with concentrations of 90 to 1080 ppm (Table 2 and Fig. 9).

\section{Discussion}

The practical application of the nanosilver composition aims to reproduce mono-dispersed nanoparticles with a well-determined style. The critical steps of accurate selection of the reducing agent and stabilizer can be more easily controlled when the nanoparticles are synthesizing. Hence, water-soluble, highly mono-dispersed and spherical AgNPS were synthesized. This is a one-pot method with an economical formulation. It is clear that this reduction of silver ions in a watery solution to silver nanoparticles is accompanied by a color change (to yellowish-brown or grayish) due to the excitation of surface plasmon vibrations in the silver nanoparticles (Gao et al. 2011; Theivasanthi and Alagar, 2011; Ramakrishna et al. 2012; Akbari et al. 2011 and Hamedi et al. 2012). The color change, as an effect of agglomeration (assembly of the particles), is a well-understood phenomenon (Mohamed et al. 2012). A safer and more economical insecticide delivery system was developed by the facile formulation of starch-silver nanoparticle-encapsulated dichlorovos and chlorpyrifos (Nnemeka et al. 2016).

The results obtained from UV-VIS spectroscopy showed the appearance of one broad peak in each AgNPS and AgNPS@P, which is due to the excitation of the SPR of silver atoms. This has been reported as describing the collective excitation of the conduction of electrons in a metal (Mohamed et al. 2012).

TEM images revealed that the silver nanoparticle-loaded profenofos complex (AgNPS@P) is mostly spherical and of a very small size. TEM micrographs were used to determine the morphology of nanoparticles and the obtained spheres (Akbari et al. 2011; Hamedi et al. 2012 and Nnemeka et al. 2016).

The FT-IR spectroscopy test detected a broad, strong band in profenofos and AgNPS@P due to the $\mathrm{O}-\mathrm{H}$ stretching vibration. Asymmetrical and symmetrical bending vibrations of the methylene groups appeared in specific peaks for both AgNPS and AgNPS@P. This may be an indication for involving the nitrile group in linkage with AgNPS (Avram and Mateescu 1972 and Abouelkassem et al. 2016). Aliphatic $\mathrm{C}-\mathrm{H}$ appeared as two strong

Table 2 Toxicity effect of silver nanoparticles (AgNPS) and profenofos compared with nanoprofenofos (AgNPS@P) against fourthinstar larvae of laboratory and field cotton leafworm, Spodoptera littoralis

\begin{tabular}{|c|c|c|c|c|c|c|c|c|c|c|c|c|c|c|}
\hline \multirow[t]{2}{*}{ Strain } & \multicolumn{4}{|c|}{ Silver (AgNPS) } & \multicolumn{5}{|c|}{ Profenofos } & \multicolumn{5}{|c|}{ Nanoprofenofos (AgNPS@P) } \\
\hline & $\begin{array}{l}\overline{\text { Conc. }} \\
\text { ppm }\end{array}$ & $\begin{array}{l}M \\
(\%)\end{array}$ & $\begin{array}{l}\mathrm{LC}_{50} \\
\text { in } \\
\mathrm{ppm}\end{array}$ & $\overline{\mathrm{RR}^{\mathrm{a}}}$ & $\begin{array}{l}\overline{\text { Conc. }} \\
\text { ppm }\end{array}$ & $\begin{array}{l}M \\
(\%)\end{array}$ & $\begin{array}{l}\mathrm{LC}_{50} \\
\text { in } \\
\mathrm{ppm}\end{array}$ & $\overline{R R^{a}}$ & $\overline{\operatorname{RRr}^{\mathrm{D}}}$ & $\begin{array}{l}\overline{\text { Conc. }} \\
\text { ppm }\end{array}$ & $\begin{array}{l}M \\
(\%)\end{array}$ & $\begin{array}{l}\mathrm{LC}_{50} \\
\text { in } \\
\mathrm{ppm}\end{array}$ & $\overline{R R^{a}}$ & $\overline{R R r^{\circ}}$ \\
\hline \multirow[t]{6}{*}{ Laboratory } & & & 6202.8 & --- & 5.63 & 6 & 45.67 & --- & 29.28 & 0.18 & 10 & 1.56 & ---- & 1 \\
\hline & 499.5 & 4 & & & 11.3 & 16 & & & & 0.36 & 16 & & & \\
\hline & 999 & 10 & & & 22.5 & 30 & & & & 0.72 & 30 & & & \\
\hline & 1998 & 26 & & & 45 & 48 & & & & 1.44 & 46 & & & \\
\hline & 3996 & 36 & & & 90 & 68 & & & & 2.88 & 60 & & & \\
\hline & & & & & 180 & 86 & & & & 5.75 & 86 & & & \\
\hline \multirow[t]{5}{*}{ Field } & & & 14,598 & 2.35 & 90 & 10 & 357 & 7.82 & 69.31 & 1.44 & 20 & 5.15 & 3.3 & 1 \\
\hline & 1998 & 6 & & & 180 & 20 & & & & 2.875 & 36 & & & \\
\hline & 2997 & 10 & & & 270 & 40 & & & & 5.75 & 50 & & & \\
\hline & 3996 & 16 & & & 540 & 66 & & & & 11.5 & 70 & & & \\
\hline & 5994 & 24 & & & 1080 & 88 & & & & 23 & 86 & & & \\
\hline
\end{tabular}

${ }^{\mathrm{a}} \mathrm{RR}$ (Resistance Ratio) $=\mathrm{LC}_{50}$ of the field strain/LC $\mathrm{C}_{50}$ of the laboratory strain

${ }^{\mathrm{b}} \mathrm{RRr}$ (Relative Resistance ratio) $=\mathrm{LC}_{50}$ of the strain/lowest $\mathrm{LC} \mathrm{C}_{50}$ values of the same strain $M$ mortality 
bands corresponding to asymmetrical and symmetrical stretching modes. $\mathrm{vC}-\mathrm{H}$ absorption bands arising from asymmetrical vibrations are stronger than symmetrical ones. The $\mathrm{C}=\mathrm{C}$ stretching vibrations for hetero-aromatic compounds were observed in the same region in both profenofos and AgNPS@P. The above findings indicate that silver nanoprofenofos was attached to the functional groups present in starch. The shifting of the peak is due to the formation of the co-ordination bond between the silver atom and the electron-rich groups (oxygen/carbonyls) present in starch. This causes an increase in bond length and frequency (Akbari et al. 2011; Hamedi et al. 2012; Abouelkassem et al. 2016 and Nnemeka et al. 2016).

The toxicity of profenofos increased 45 and 85 times to the second-instar larvae of both laboratory and field cotton leafworm when it became nanoprofenofos. This increase in toxicity was more than 29 and 69 times for the fourth-instar larvae of laboratory and field larvae. In addition, the field fourth-instar larvae were more resistant to AgNPS, profenofos and AgNPS@P than the laboratory strain, where the Resistance Ratio (RR) was 2.35-fold, 7.82-fold and 3.3-fold, respectively. Other findings of Abouelkassem et al. (2016) indicated that silver-cyhalothrin nanocomposite is more efficient in controlling mosquito larvae than is free cyhalothrin. Therefore, this formulation should produce a synergetic effect to combat the adverse effects of the conventional insecticides on the environment (Nnemeka et al. 2016).

\section{Conclusions}

From this study, it can be conclude that nanoprofenofos (AgNPS@P) has a very toxic effect on the cotton leafworm, Spodoptera littoralis compared to the original pesticide (profenofos). Therefore, we can use small amounts of the novel synthetic nanocomposite pesticide in the management of pests to reduce their resistance to conventional pesticides and reduce environmental pollution.

\section{Acknowledgements}

The authors thank the Pesticides Analysis and Mammalian Toxicology Departments in the Central Agricultural Pesticides Laboratory for all their assistance in this work

\section{Funding}

There was no funding for this work.

\section{Availability of data and materials}

All data generated during this study are included in this published article.

\section{Authors' contributions}

All authors contributed in the production and writing of the manuscript. All authors read and approved the final manuscript.

\section{Ethics approval and consent to participate}

The manuscript does not contain any studies involving human participants, human data or

human tissue.
Consent for publication

Not applicable.

\section{Competing interests}

The authors declare that they have no competing interests.

\section{Publisher's Note}

Springer Nature remains neutral with regard to jurisdictional claims in published maps and institutional affiliations.

\section{Author details}

${ }^{1}$ Central Agricultural Pesticides Laboratory, Agricultural Research Centre, Giza, Egypt. ${ }^{2}$ Department of Natural Resources, Institute of African Research and Studies - Cairo University, Cairo, Egypt. ${ }^{3}$ Nanotechnology Research Center, British University in Egypt, Cairo, Egypt. ${ }^{4}$ Nanotechnology and Advanced Materials Central Laboratory, Agricultural Research Centre, Giza, Egypt.

Received: 29 September 2018 Accepted: 18 February 2019

Published online: 22 March 2019

\section{References}

Abbott WS (1925) A method of computing the effectiveness of an insecticide. J Econ Enotomol 18:265-267

Abouelkassem S, El-Borady OM, Mona BM (2016) Remarkable enhancement of cyhalothrin upon loading into silver nanoparticles as larvicidal. Int J Contemp Appl Sci 3(1):252-264.

Akbari B, Pirhadi T, Zandrahimi M (2011) Particle size characterization of nanoparticles: a practical approach. Iran J Mater Sci Eng 8(2):48-56

Avram M, Mateescu DG (1972) Infrared spectroscopy, applications in organic chemistry. Wiley, New York

Bhattacharyya A, Bhaumik A, Usha Rani P, Mandal S, Epidi TT (2010) Nanoparticles: a recent approach to insect control. Afr J Biotechnol 9:3489-3493

Croft BA (1990) Arthropod biological control agents and pesticides. Wiley, New York

Eddleston M, Worek F, Eyer P, Thiermann H, Von Meyer L, Jeganathan K, Sheriff MH, Dawson AH, Buckley NA (2009) Poisoning with the S-alkyl organophosphorus insecticides profenofos and prothiofos. QJM 102(11):785792. https://doi.org/10.1093/qjmed/hcp119 PMC 2766103 . PMID 19737786

El-Aswad AF, Abdelgaleil SAM, Nakatani M (2003) Feeding deterrent and growth inhibitory properties of limonoids from Khaya senegalensis against the cotton leafworm, Spodoptera littoralis. Pest Manag Sci 60:199-203

El-Zemaity MS, El-Deeb WM, Osman YA, Hussien Al (2003) Development of resistance of Spodoptera littoralis to certain bioinsecticides. J Environ Sci 6: 793-810

Finney DJ (1971) Probit analysis, vol 333, 3rd edn. Cambridge University Press, Cambridge, $\mathrm{p} 3$

Gao X, Ligiao W, Jing X (2011) Green synthesis of starch-stabilized silver nanoparticles and their antibacterial properties. Appl Chem Eng Res 2011(236-238):1945-1948

Haick H (2007) Chemical sensors based molecularly modified metallic nanoparticles. J Phys D Appl Phys 40(23):7173-7186

Hamedi S, Masumeh S, Shojaosadati S, Soheila S (2012) Comparative study on silver nanoparticles properties produced by green methods. Iran J Biotechnol 10(3):191-197

Hatem AE, Azazy AM, Salwa SM, El-Samad A, Reda AMA (2011) Toxicity and bioactivity of feeding cotton leaf worm, Spodoptera littoralis (Boisduval) (Lepidoptera: Noctuidae) larvae on fresh leaves of selected weeds. J Plant Prot Pathol, Mansoura Univ 2(3):257-273

Kuzma J, Romanchek J, Kokotovich A (2006) Upstream oversight assessment for agrifood nanotechnology: a case studies approach. Risk Anal 28:1081-1098

Mohamed MB, Adbel-Ghani NT, El-Borady OM, El-Sayed MA (2012) 5-fluorouracil induces plasmonic coupling in gold nanospheres: new generation of chemotherapeutic agents. J Nanomed Nanotechnol 3(7):146-153

Nkya TE, Idir A, Rodolphe P, Bernard B, Franklin M, Stephen M, William K, JeanPhilippe D (2014) Insecticide resistance mechanisms associated with different environments in the malaria vector Anopheles gambiae: a case study in Tanzania. Malar J 13:28

Nnemeka El, Rufus S, Terrumun AT, Lami AN, Philip B, Bertrand S, Malik M (2016) Facile formulation of starch-silver-nanoparticle encapsulated dichlorvos and chlorpyrifos for enhanced insecticide delivery. New J Chem 40:1777-1784 
Onwuka IO (2015) Environmental sustainability and job creation - A critical symbiosis for growth in Nigeria. Int J Innov Environ Stud Res 3(4):1-12

Ramakrishna V, Rima P, Apurba K (2012) Synthesis and characterization of CeO2 nanoparticles via solution combustion method for photocatalytic and antibacterial activity studies. Nanomater Nanotechnol 2:8

Report FAO and WHO (2009) Sponsored jointly by FAO and WHO with the support of the International Program on Chemical Safety; Joint Meeting of the FAO Panel of Experts on Pesticide Residues in Food and the Environment and the WHO Core Assessment Group, Geneva, Switzerland, 18-27 September (2009)

Rotello VM (2003) Nanoparticles: building blocks for nanotechnology, 1st edn. Springer, New York

Salahuddin S, Siti HA, Hidayatul fO (2004) Residual efficacy of insect growth regulators pyriproxyfen, triflumuron and s-methoprene against Aedes aegypti (L.) in plastic containers in the field. Trop Biomed 21:97-100

Sanni BN, Mutta RS (2014) Impact of solvents leading to environmental pollution. J Chem Pharm Sci:49-52 Special Issue 3: October

Sooresh A, Hyeogsun K, Robert T, Patricia P, Michelle P, Christie MS (2011) Surface functionalization of silver nanoparticles: novel applications for insect vector control. ACS Appl Mater Interfaces 3:3779-3787

Tali D (2009) Synthesis of uniform silver nanoparticles with a controllable size. Mater Lett 63(2009):2236-2238

Theivasanthi T, Alagar M (2011) Electrolytic synthesis and characterizations of silver nanopowder. arXiv:1111.0260(physics - gen. physics)

Thomas CS, Ralf N (2015) IRAC: mode of action classification and insecticide resistance management. Pestic Biochem Physiol 121:122-128

Vimala K, Yallapu MM, Kokkarachedu V, Nagireddy NR, Sakey R, Neppalli SN, Konduru MR (2011) Fabrication of curcumin encapsulated chitosan-PVA silver nanocomposite films for improved antimicrobial activity. J Biomater Nanobiotechnol 2:55-64. https://doi.org/10.4236/jbnb

Zhang J, Li M, Fan T, Xu Q, Wu YC (2013). Construction of novel amphiphilic chitosan copolymer nanoparticles for chlorpyrifos delivery. J Polym Res 20:107-118

\section{Submit your manuscript to a SpringerOpen ${ }^{\circ}$ journal and benefit from:}

- Convenient online submission

- Rigorous peer review

- Open access: articles freely available online

- High visibility within the field

- Retaining the copyright to your article

Submit your next manuscript at $\boldsymbol{\nabla}$ springeropen.com 